\title{
Linking Molecular Physiology to Ecological Realities ${ }^{\star}$
}

\author{
Steven L. Chown ${ }^{1, \dagger}$ \\ Kenneth B. Storey ${ }^{2}$ \\ ${ }^{1}$ Centre for Invasion Biology, Department of Botany and \\ Zoology, University of Stellenbosch, Private Bag X1, \\ Matieland 7602, South Africa; ${ }^{2}$ Institute of Biochemistry, \\ Carleton University, 1125 Colonel By Drive, Ottawa, Ontario \\ K1S 5B6, Canada
}

Accepted 11/2/2004; Electronically Published 2/8/2006

\begin{abstract}
Although molecular physiology and ecology have drifted apart as a consequence of early separation in the questions posed and techniques used, there is a resurgence of interest in forging links between them. Here we explore the reasons for this renewed interest and provide four examples of how this is happening. Specifically, we examine links between molecular physiology and ecological realities in insect responses to thermal stress, vertebrate responses to anoxia, metabolic fuel use and torpor in mammals, and the recently developed "metabolic theory of ecology." Several novel insights are emerging from integrated approaches to these problems that might not have come forward from any single perspective on them. Nonetheless, prospects for linking molecular physiology and ecological realities are likely to remain poor if greater focus is not given to developing these links. Mostly, this is a consequence of the differing approaches and "languages" adopted by these fields. We discuss approaches by which the prospects for synthetic work might be improved.
\end{abstract}

\section{Introduction}

Browsing the contents pages of the American Naturalist and Physiological Zoology from the early 1900s quickly demonstrates that during this period there was little that distinguished ecology and physiology from each other. Papers routinely addressed

\footnotetext{
* This paper was prepared as an overview of a symposium session presented at "Animals and Environments," the Third International Conference for Comparative Physiology and Biochemistry, Ithala Game Reserve, KwaZulu-Natal, South Africa, 2004 (http://www.natural-events.com/ithala/default-follow_2.asp).

†Corresponding author. E-mail: slchown@sun.ac.za.
}

Physiological and Biochemical Zoology 79(2):314-323. 2006. (C) 2006 by The University of Chicago. All rights reserved. 1522-2152/2006/7902-4137\$15.00 the links between these fields, and finding physiological work in the former journal and ecological questions in the latter was not unusual. However, developments in both fields changed all of that. By the latter part of the last century, the barrier between the fields was, if not impermeable, certainly crossed with a much lower frequency than had been the case in the past. Ecology's gaze was fixed on population regulation and interactions, while that of physiology was generally turning inward to lower levels in the physiological hierarchy as the mechanistic tools to explore them became increasingly accessible (Spicer and Gaston 1999; McNab 2003).

In many ways, this divergent course has been set by and continues to be followed because of the compartmentalization that is the reality of modern science. Biologists in different subdisciplines find themselves in different "solitudes"-vocational separation and isolation based on ideas and concepts used, on testable hypotheses employed, on experimental methodology available, and on publishing norms that do a poor job of conveying ideas outside a narrow "in-group." However, recent years have seen a dramatic resurgence of interest in bridging these solitudes or at least forging better links between them. This desire for improved integration has clearly arisen for a wide variety of reasons (see discussions in Spicer and Gaston 1999; McNab 2003; Chown et al. 2004), but four strike us as most noteworthy.

First, sound comprehension of the evolution of physiological responses and the mechanisms underlying them plainly requires incorporation of their ecological, phylogenetic, and paleontological contexts (Huey 1987; Garland and Carter 1994; Clarke 1996; Feder et al. 2000). Second, ecology, in both its pure and its more applied forms (e.g., pest management and conservation biology), is making an increasing number of assumptions about the ways in which organisms respond to their abiotic environments (see discussion in Chown and Clarke 2000; Gaston 2003; Chown and Nicolson 2004). Third, much of life-history theory is concerned with the ways in which organisms acquire and use energy and information to maximize fitness, issues that are by their very nature physiological (e.g., Roff 1992; Stearns 1992). Fourth, the higher levels of biological organization must be well worked out before molecular studies, which are essential for elucidating the mechanistic basis of responses to the environment and for fully comprehending their associated trade-offs (e.g., Zhao and Zera 2002; Zera 2004; Zera and Zhao 2004), can be undertaken. Successful molecular science requires testable hypotheses-testable at the molecular level.

Effectively, it has again become clear that if we are to understand how organisms maximize fitness in the face of both changing and variable environments, which in turn determines 
variation in strategy, abundance, and range size and in so doing results in the diversity of life we see today, then linking ecological realities and molecular mechanisms in a new synthesis for this century is imperative. Here we bring together four examples from the session "Linking Molecular Physiology to Ecological Realities" at the Third International Conference of Comparative Physiology and Biochemistry, held in South Africa, to show where this is starting to happen.

\section{Coping with Cold and Heat}

Temperature is one of the most significant abiotic factors determining the distribution and abundance of life on Earth. Directly, it limits animal distributions by exceeding thresholds for survival, development, and reproduction (Cossins and Bowler 1987; Feder et al. 1997; Spicer and Gaston 1999; Dahlhoff and Rank 2000; van der Have 2002) and by altering rates and processes over both ecological and evolutionary time (Cossins and Bowler 1987; Rohde 1992: Hochachka and Somero 2002; Evans et al. 2005). Indirectly and in combination with water availability, it determines available energy, which has a major influence on the number of individuals that can occur in an area and therefore, ultimately, the area's species richness (Hawkins et al. 2003; Willig et al. 2003; Evans et al. 2005). For this reason, temperature variation and its effects on animals have long fascinated biologists (e.g., Shelford 1911; Andrewartha and Birch 1954). The current and likely future effects of global climate change (Davis and Shaw 2001; Walther et al. 2002; Root et al. 2003; Thomas et al. 2004) have given this interest renewed urgency, and much attention is now being paid to geographic variation in tolerances, how much of this variation is a consequence of basal responses as opposed to phenotypic plasticity, how much scope there is for evolutionary change in both, and what the biochemical and molecular bases are for these responses (e.g., Stillman and Somero 2000; Denlinger et al. 2001; Angilletta et al. 2002; Hoffmann et al. 2003; Stillman 2003).

Insects have long been useful models for investigating ectotherm responses to temperature, owing to both their diversity and the tractability of some species as model organisms (Andrewartha and Birch 1954; Parsons 1981). While investigations of geographic variation in insect responses to temperature have a venerable history (Scholander et al. 1953; Messenger 1959), recent large-scale, or macrophysiological (Chown et al. 2004), studies have revealed several novel and consistent patterns. At global, regional, and local scales, it appears that the range of upper thermal tolerances is lower than the range of lower thermal tolerances and that the former shows much greater variation with either latitude or altitude than the latter. This is true of basal responses (Addo-Bediako et al. 2000; Chown 2001) and also appears to be typical of induced responses such as those associated with cold and heat hardening (Chen et al. 1990), although variation in induced responses can sometimes appear counterintuitive. For example, populations of Drosoph- ila species from warm areas tend to have a reduced heat shock response compared with those from cooler environments (Sørensen et al. 2001; Zatsepina et al. 2001), mostly because repeated expression of heat shock proteins is likely to mean a reduction in fitness. In laboratory acclimation experiments, there also appears to be a reduced response to high temperatures compared with that to low temperatures (e.g., Klok and Chown 2003). Indeed, in some cases it appears that acclimation responses to low temperatures can be sufficiently large to account for all of the geographic variation shown in cold tolerance at both small (Klok et al. 2004) and large (Ayrinhac et al. 2004) spatial scales. Laboratory selection experiments have revealed similar differential responses to heat and cold (Gilchrist et al. 1997; Hoffmann et al. 1997).

Although there are notable and important exceptions to these generalizations (Hoffmann et al. 2002; Sgrò and Blows 2004), it does appear that high- and low-temperature responses are decoupled in insects, unlike the case in many other ectotherms, especially those from marine environments (Prosser 1986; Cossins and Bowler 1987). Recently, Pörtner (2001, 2002) has suggested that thermal tolerance limits in marine organisms might be set as a consequence of insufficient mitochondrial aerobic capacity at low temperatures and a mismatch between oxygen demand and delivery at high temperatures and that this might also account for coupled upper and lower lethal temperatures. Several recent studies on insects have explored these ideas either explicitly or implicitly (Klok et al. 2004; Koštál et al. 2004; Sinclair et al. 2004; Woods and Hill 2004). The data indicate that oxygen limitation most likely does not set upper lethal limits, probably as a consequence of the efficient tracheal oxygen delivery systems that are characteristic of insects. However, it might well contribute to lethal limits at the low end of the temperature scale (Hosler et al. 2000; Sinclair et al. 2004). Thus, it is not higher-level failure of delivery systems that sets thermal limits in insects but, probably, the extent of cellular level responses. These include the expression of stress proteins and the production of polyols and antifreeze proteins (reviewed in Chown and Nicolson 2004).

The role of heat shock proteins (Hsps) in protecting insects against heat, cold, and desiccation stress, both during diapause and when it is broken, is becoming increasingly well understood (Yocum et al. 1991; Goto and Kimura 1998; Rinehart et al. 2000; Denlinger et al. 2001). Differences in the time course of Hsp expression for heat and cold shock have been demonstrated in a variety of insects. During heat shock, Hsps are synthesized during the stress, and synthesis ceases almost immediately on cessation of the stress (Denlinger and Yocum 1998). By contrast, after cold shock, Hsp synthesis commences only after the animals have been returned to a higher temperature and may then continue for days (Denlinger and Lee 1998). It is also clear that there is an interaction with diapause such that stress proteins that normally interfere with cellular growth and differentiation can be upregulated continuously because of cell 
cycle arrest (Denlinger et al. 2001). Recent work has demonstrated that Hsp 70 RNA interference (RNAi) affects cold tolerance, so supporting the role of Hsp70 in conveying tolerance, and it is well established that Hsp90 and HSc70, which are constitutively expressed in Sarcophaga crassipalpis, are upregulated after both cold and desiccation exposure (Hayward et al. 2004).

Rapid cold hardening refers to the reduction in cold shock mortality that can be induced by a short-term exposure to a sublethal temperature before the cold shock (Lee et al. 1987). It is thought to be of considerable ecological importance because it enables animals to respond to short-term changes in temperature (Kelty and Lee 2001) without the need for deployment of the full suite of biochemical responses that characterizes longer-term cold hardiness (see Ramløv 2000), which usually takes several weeks. Although rapid cold hardening is not typical of all insects (Sinclair and Chown 2003), it has been found in the large majority of those that have been investigated (Chown and Nicolson 2004). In their original investigations, Lee et al. (1987) found that the rapid cold-hardening response is associated with an upregulation of glycerol, although this response is not consistent across all species. However, other studies have shown that in all of the species investigated, both Hsp70 and Hsp23 (and several other stress proteins) are upregulated in response to cold shock (see Yocum et al. 1991; Denlinger et al. 1992; Denlinger and Lee 1998; Yocum 2001). Indeed, recent work by Denlinger and colleagues has shown that RNAi of hsp23 causes a significant and substantial reduction in survival of cold shock following hardening in the flesh fly S. crassipalpis, so substantiating the significant role of Hsp23 in the rapid cold hardening response. By contrast, the same response was not found with RNAi of $h s p 70$, leaving the upregulation of Hsp70 during rapid cold hardening unexplained. Nonetheless, this work has provided substantial insight into the molecular underpinnings of those strategies that enable insects to cope with both temporal and spatial variation in the thermal environment. Thus, the link between molecular mechanisms underlying responses to temperature and the ecological implications thereof is, in this instance, clearly two-way. Comparative work at ecological scales supports the role of cellular-level responses, while the molecular approach elucidates just how these might have evolved.

\section{Surviving Anoxia}

The majority of species on Earth have evolved to take advantage of the high ATP yields that are derived from the oxygendependent catabolism of metabolic fuels in mitochondria. Interruption of oxygen supplies to tissues is rapidly fatal to humans and most other mammals, but a variety of vertebrate (and many invertebrate) species have developed effective mechanisms for long-term survival under hypoxic or even anoxic conditions. Studies at the ecological, physiological, and bio- chemical levels using freshwater turtles as model systems are documenting the range of strategies that are combined to provide anoxia tolerance to these remarkable animals. Freshwater turtle species hibernate underwater, and in northern latitudes, this can result in many weeks of continuous submergence in ice-covered ponds (Ultsch 1989). Lung breathing becomes impossible, but aquatic gas exchange can be used in some cases. Often, however, ice-locked aquatic habitats become oxygen depleted, and animal survival is then dependent on anaerobic metabolism. Hypoxia-intolerant species, such as the soft-shelled turtle Apalone spinifera, select dependably oxygenated sites for overwintering and remain largely aerobic by utilizing aquatic gas exchange (Reese et al. 2003). Hypoxia-tolerant species, such as the painted turtle Chrysemys picta, can survive in ponds and lakes that may become stagnant and hypoxic; indeed, they can endure submergence in anoxic water for up to $5 \mathrm{mo}$ at $3^{\circ} \mathrm{C}$. To do so, they have optimized two major strategies: (1) metabolic-rate depression that achieves a coordinated suppression of all metabolic reactions and (2) effective buffering to slow the accumulation of lactic acid produced from anaerobic glycolysis and to limit the resulting acidosis (Jackson 2000, 2002). Recent work has made extensive progress in understanding this second strategy and revealed the central importance of the turtle's shell. Two separate shell mechanisms are involved: (1) the release of calcium carbonate from the shell buffers the accumulating products of anaerobic glycolysis (lactate anion and $\mathrm{H}^{+}$), and (2) lactate is removed from circulation and taken up into the shell itself, where it is buffered and sequestered. Together, the metabolic and buffering mechanisms permit stabilization of blood $\mathrm{pH}$ in the face of circulating lactate levels that can rise to $150 \mathrm{mmol} \mathrm{L}^{-1}$ or higher (Reese et al. 2001; Jackson 2004).

These studies are not only important in their own right but also critical to development of the field of vertebrate anaerobiosis. Because they have solid and complete information about turtle behavior in the wild, the physiological ecology of overwintering, and the patterns of change in multiple metabolic parameters (e.g., metabolic rate, plasma $\mathrm{pH}$ and ions, endproduct accumulation), other scientists have been able to continue the story of anoxia tolerance down to the molecular and gene levels. Studies of important model organisms, such as freshwater turtles, illustrate and define the elastic limits to which biochemical adaptation can be stretched to cope with environmental stress and allow us to reach a full understanding of functional metabolism-the regulation and adaptation of life on Earth (Storey 2004a).

One of the key early observations made by Jackson and colleagues (Jackson 1968; Ultsch 1989) was the strong suppression of metabolic rate during submergence in pond turtles of the genera Trachemys and Chrysemys. For example, the metabolic rate of $C$. picta submerged in cold water is only about $10 \%$ of the corresponding rate in air at the same temperature. By strongly suppressing metabolic rate in anoxia, as well as 
reorganizing the priorities for ATP use, organisms gain a major extension of the time that they can survive using only anaerobic pathways for ATP production.

The biochemical mechanisms that regulate anoxia-induced metabolic-rate depression in turtles are the focus of research in several labs (Bickler et al. 2002; Lutz and Milton 2004; Storey and Storey 2004; Storey 2004b). Metabolic arrest targets both ATP-producing processes, such as fuel utilization, and ATPutilizing processes, such as ion pumping, transcription, and translation, using two main principles: (1) the reversible suppression of the rates of multiple cell enzymes, pathways, and processes using reversible biochemical controls, such as covalent modification of key enzymes; and (2) the anoxia-induced expression of selected genes to produce protein products with specific functions in the anoxic cell (Storey and Storey 2004; Storey 2004b). The primary mechanism for reversible suppression of cellular enzymes and functional proteins under anoxia (and in multiple other hypometabolic states) has proved to be the addition or removal of covalently bound phosphate, carried out by protein kinases and protein phosphatases (Storey and Storey 2004). For example, several enzymes of the ATPgenerating glycolytic pathway are coordinated in this manner under anoxia in turtles, including glycogen phosphorylase, phosphofructokinase 1 and 2, and pyruvate kinase. Proteins involved in ion homeostasis (pumps and channels), transcription, and translation are also reversibly suppressed in this way.

However, despite global transcription and translation suppression in anoxia, selected genes are upregulated. This is achieved via the actions of specific transcription factors under the control of specific anoxia-responsive protein kinases. For example, prominent in the response to anoxia by turtle organs is the activation of c-Jun N-terminal kinase (JNK), whose activity peaks after $5 \mathrm{~h}$ of anoxic submergence (Greenway and Storey 2000). JNKs function specifically in mediating changes in gene expression. Much recent work has focused on which genes are upregulated in response to anoxia, utilizing two techniques: cDNA library screening and DNA array screening. These studies are providing novel insights into gene expression changes that support anoxia tolerance by documenting upregulation of genes that code for proteins with diverse functions; these include proteins in the mitochondrial respiratory chain (Cai and Storey 1996; Willmore et al. 2001), solute carriers, antioxidant enzymes, shock proteins, and protease inhibitors. In particular, recent studies using cDNA array screening have revealed the novel upregulation in anoxia of protease inhibitors, particularly several serpins (serine protease inhibitors; Storey 2004b). Many serpins are irreversible covalent inhibitors of proteases that act at critical checkpoints in the proteolytic cascades involved in blood coagulation, inflammation, and other responses. Upregulation of these serpins suggests that one aspect of long-term anaerobic survival may be inhibition of proteolytic reactions and cascades that could otherwise cause cu- mulative damage to tissues over the long term in an energy-restricted state.

Hence, new explorations of anoxia-induced gene expression are producing many novel leads into areas of metabolic function that have never been considered as contributing to facultative anaerobiosis. For the comparative biochemist, these opportunities for significant new discoveries are exciting; for the physiological ecologist, they offer insights into how animals cope with anoxia and what might limit animals in achieving survival.

\section{Meeting Energetic Challenges}

Fuel use and its regulation in mammals are important from a range of perspectives from human athletic performance to torpor and hibernation in other mammals. How fuel levels and usage rates vary at the whole-animal level and what the molecular-level controls are that can be used to suppress fuel/ energy use by multiple cell functions (e.g., transcription, translation, carbohydrate catabolism) to allow entry into torpor and/ or hibernation are clearly topics that provide linkages between molecular mechanisms and the ecological realities that animals face.

To match ATP supply with demand, mechanisms must be in place to ensure adequate delivery of metabolic fuels and oxygen to mitochondria. The mixture of fuels used (fats, carbohydrates, proteins) and their individual flux are tightly orchestrated to cope with changing physiological needs (Storey $2004 a$ ). The control of fuel selection under environmental stress shows many common themes across evolution, although with a few recently uncovered apparent exceptions. ATP turnover is continuously adjusted, often on a minute-by-minute basis. Instantaneous fuel use is determined by multiple, interacting mechanisms involving fuel availability, storage location, muscle recruitment, fiber recruitment within each muscle, and metabolic pathway selection within each fiber (Haman et al. 2004b). ATP flux can change enormously in response to physiological demands, for example, being increased sharply in exercise, cold exposure, and lactation or being decreased during fasting or diving or in torpor/hibernation. In general, of total fuel reserves, $85 \%$ are lipids, making this fuel a major target of evolutionary adaptation. Central to our understanding of fuel use is the constancy of this dominant use of lipids under resting conditions and low exercise intensity. By contrast, carbohydrates have a more limited pattern of use as fuels. They are key when oxygen is limiting but are used increasingly as exercise intensity rises, becoming the major fuel as exercise intensity nears the aerobic maximum. This is a constant pattern, seen across phylogeny regardless of aerobic capacity, body size, or various environmental stresses.

Surprisingly, new data show that shivering has a different pattern of fuel use than does exercise (Haman et al. 2002, 2004a, $2004 b, 2004 c$ ), a remarkable finding in a field where it was 
thought that muscle fuel use patterns were all well understood. These studies show that new paradigms are required to fully understand the use of fuels in different types of muscle work, for example, shivering and long-distance migration. Hence, exciting unknowns remain to be explored in a field with a very long history where no major changes were expected. As the physiological realities of these fuel choice patterns emerge, they will be a very fertile field for biochemical and molecular genetic studies.

Hibernation and daily torpor are the most powerful measures that endotherms can use to reduce their energy consumption (Heldmaier et al. 2004). In torpid states, organisms drop their metabolic rate to just a fraction of the normal resting metabolic rate; for example, during daily torpor, Djungarian hamsters reduce their metabolic rate by more than $70 \%$ for several hours while sleeping. Metabolic suppression affects multiple (perhaps all) aspects of metabolism. For example, using the nuclear runon technique, the rate of transcriptional initiation in hamster liver was shown to be reduced by $40 \%$ during torpor but rebounded fully after arousal (Berriel Diaz et al. 2004). Protein synthesis is also strongly suppressed during torpor/hibernation, as documented by analysis of the relative activity of the translational machinery (e.g., polysome content and active mRNA transcripts). For example, torpor is marked by a disaggregation of transcriptionally active polysomes that indicate that the overall rate of protein synthesis is strongly reduced. Carbohydrate catabolism is also slowed in torpor/hibernation, and this is regulated at least in part by inhibition of pyruvate dehydrogenase, the enzyme that gates entry of carbohydrate fuels into the mitochondria (Heldmaier et al. 1999). Regulation is applied via posttranslational covalent modification of the enzyme. Taken together, these events and others resculpt cells and tissues to suppress ATP turnover, reduce heat production, and allow substantial energy savings. A particularly important advance in our understanding of the overall role and origin of torpor/ hibernation in mammalian biology was revealed by recent work on Madagascan lemurs (Dausmann et al. 2004). The fat-tailed dwarf lemur Cheirogaleus medius hibernates for several months of the year, even though ambient temperatures during this time can range up to $30^{\circ} \mathrm{C}$. Hence, in this instance, hibernation is not necessarily coupled to a low body temperature, which challenges the idea that hibernation arose as a mechanism of winter cold hardiness. Instead, this study points to a more general and ancient role of hibernation as a measure to cope with a seasonal interruption of food/fuel supplies. Thus, as these examples from human shivering and mammalian hibernation demonstrate, new principles are still being discovered, and much still remains to be learned about the selection and regulation of fuel use and the strategies for matching fuel supply to physiological demand and environmental stress.

\section{Scaling Up to Diversity}

One of the most significant and potentially unifying ideas providing links from the molecular level through to the ecological level is the nutrient supply network model for metabolic scaling proposed by Brown, West, Enquist, and their colleagues (West et al. 1997, 1999, 2002), which they have widely explored and termed the "metabolic theory of ecology" (Brown et al. 2004a). The model builds on several key assumptions. These include that the rate at which energy is dissipated is minimized, that transport systems have a space-filling, fractal-like branching pattern, that the final branch of the network is size invariant, and that branching patterns preserve cross-sectional area. From these and other assumptions, the quarter-power metabolic (and other) scaling that is apparently typical of all groups (e.g., Savage et al. 2004) can be derived. Indeed, building on the premise that metabolic rate is the most fundamental biological rate process, West et al. (1997, p. 126) have claimed that quarterpower scaling is the "single most pervasive theme underlying all biological diversity." Later work has incorporated the temperature dependence of whole-organism metabolism, and the Van't Hoff-Arrhenius relation is thought to describe this temperature dependence relatively well across all organisms, from unicellular microbes to multicellular animals and plants (Gillooly et al. 2001). The combined temperature and scaling equation has subsequently been used to make comparisons across organisms that differ substantially in their forms and life histories. Brown and colleagues argue that this metabolic theory predicts how metabolic rate, by setting rates of resource uptake and allocation, controls ecological processes at all levels of organization, from life-history attributes through population processes to those at the ecosystem level, and eventually also determines large-scale variation in biodiversity (for review, see Gillooly et al. 2001; West et al. 2001; Allen et al. 2002; Brown et al. 2004a). Brown et al. (2004a) emphasize that this metabolic theory is one that encompasses all levels from the molecular to the ecological and argue that it explains much of the diversity that is the most characteristic and significant feature of life on Earth.

Like all general models, the metabolic theory proposed by Brown, West, and Enquist is controversial (and should perhaps at this point be termed the "metabolic hypothesis"). There have been vigorous discussions in the literature regarding the underlying theory, its biological assumptions, the empirical relationships predicted by the model and found in nature, and the extent to which the metabolic theory will prove useful for addressing questions in community and population ecology (e.g., Dodds et al. 2001; Symonds and Elgar 2002; Ricklefs 2003; Clarke 2004; Clarke and Fraser 2004; Cyr and Walker 2004; Finkel et al. 2004; Kozłowski and Konarzewski 2004; Sterner 2004; Tilman et al. 2004). Brown, West, Enquist, and their colleagues have only begun responding to these critiques (e.g., Savage et al. 2004; Brown et al. 2004b), and for many of the 
issues the jury remains out. Proponents on both sides claim that their explanation is the one that best fits the data, makes the most realistic assumptions, or has the most generality.

Time, careful investigations of the models' assumptions, additional theoretical analyses, and additional empirical data will tell. However, they will do so only if the metabolic theory is given the close inspection that it deserves, from the molecular to the ecological level, especially because it is one of the few models that encompass the full range of the hierarchy (see Brooks and Wiley 1988 and Kauffman 1993 for other approaches, including one that incorporates the genealogical hierarchy). While there is clearly much that this metabolic theory does not explain (e.g., Brown et al. 2004a; Tilman et al. 2004), and while it might end up being subject to considerable modification and possibly eventual disproof, it is of heuristic value because of the attention it has drawn to the ways in which molecular mechanisms and ecological realities are linked and the importance of exploring these links. Moreover, it also draws attention to a fundamentally applied question: what the effect of such enormous and expanding use by humans of global energy input will be on the biodiversity that is the mainstay of our existence (Gaston 2004; Li et al. 2004).

\section{Lessons}

Our rationale for organizing a symposium session on linking molecular physiology to ecological realities was not to determine whether this is possible. We believe that it is and that doing so is important (see also Storey and Storey 2000; Chown et al. 2003). Rather, we wanted to ascertain the extent to which such linkages might be forged, where and how this is already happening, and what insights might be gained beyond those that are a consequence of more narrow "molecular" and "ecological" approaches. From the above discussion, it is clear that links between molecular physiology and ecological realities continue to be forged and that these links are producing a range of insights beyond those that might be achieved by adopting only a single approach. Achieving these insights is important not only for a fundamental understanding of how life works. It also has practical applications ranging from those concerned with resolving the metabolic basis of human disease and performance under a range of conditions to those that encompass the human-environment interaction, including the welfare of the planet's diversity. These form the bases of a reasonable physiological and psychological quality of life. Indeed, one of the most pressing ecological realities facing all species, including humans, is the increasing level of environmental stress and variation that humans have precipitated as a consequence of their own phenomenal reproductive success (Cohen 1996). Coping with this reality is a pressing concern for society (Sala et al. 2000; Tilman et al. 2002; Watson 2002; Parmesan and Yohe 2003).

However, we are also aware that there is considerable selec- tion, if only indirect, against the continued establishment of these links. As we have pointed out, much of the reality of modern science of all types is compartmentalization. The molecular literature is largely inaccessible to ecologists - and only slightly more transparent to physiologists. It is hidden in plain sight, burdened by (1) the extensive use of jargon and complexity that makes the straightforward seem mystical, (2) the use of technologies that nonmolecular scientists feel cannot be either learned or applied to their system, (3) the increasingly posthypothesis nature of some of the genomic and proteomic work, such that huge amounts of data are presented in undigested lumps, and (4) the publication of papers in the diverse biochemical and genetic literature, where most of the papers are on systems of no interest to the comparative community. This last problem is somewhat compensated for by "overlap" journals where the two worlds can meet in one journal. However, the weakness of some of these overlap/comparative journals is that they have relatively small impact, and they give relatively little attention to producing easy-to-understand reviews that would inform their diverse readership, in favor of publishing narrow, specialist-read-only papers.

The ecological and ecophysiological literature is bypassed by molecular scientists for some of the same reasons, including the use of speciality journals and the seeming lack of connection of the ecological to the molecular level (the books by Brooks and Wiley [1988] and Kauffman [1993] and many of the papers we have cited here are notable exceptions). More serious are the unique reasons that much physiological ecology work is not now and will never be followed up at the molecular level. (1) While ecology and physiology papers are more hypothesisdriven than most molecular papers, they often require molecular scientists to digest voluminous literatures on complex ecosystems, statistics, and other aspects that they cannot readily interpret in order to obtain what they most crave: unity. (2) Common themes, testable at the molecular levels, are the only ones that can be explored because of the costly and timeconsuming nature of molecular searches. (3) The higher levels of biological organization must be worked out before molecular studies can be undertaken. In A Streetcar Named Desire, Blanche DuBois voiced a lament echoed by molecular scientists everywhere, "I have always relied on the kindness of strangers." Only after the higher levels of organization are worked out for different biological systems can testable and significant hypotheses at the molecular level become apparent. The gap between the generation of most current ecophysiological hypotheses and the reality of molecular work remains a critical problem in comparative science. What, then, is the prospect for ongoing integration of molecular physiology and ecological realities? This depends on how we elect to take what Ortega y Gasset (1930) called the barbarism of specialization but many others would term its success and make it work to our advantage. In our view, it will require groups thinking of bridging these levels of biological organization to select a paradigm for future work 
ranging from (1) growth of individual labs to huge sizes to cover experimental needs of studies that range from ecology to molecular biology to (2) movement of ecologically trained students, postdoctoral fellows, and other scientists to take up molecular studies in collaborative labs to (3) "handing off" the ecological and physiological knowledge of selected organisms to willing molecular labs to continue studies using their own personnel. Whatever the route, it is clear that there is much to be gained by linking molecular physiology to ecological realities.

\section{Acknowledgments}

This work emerged as a synthesis of the papers presented and discussions held in the session "Linking Molecular Physiology to Ecological Realities" at the Third International Conference of Comparative Physiology and Biochemistry, Ithala, South Africa. We thank James Brown, Andrew Clarke, David Denlinger, Gerhard Heldmaier, Donald Jackson, and Jean-Michel Weber for generously agreeing to contribute to the session and for making their sometimes unpublished work available to us. Steve Morris and André Vosloo organized an excellent meeting. J. M. Storey and two anonymous reviewers provided useful comments on a previous draft of the manuscript. S.L.C. is supported by the National Research Foundation and K.B.S. by the Natural Sciences and Engineering Research Council of Canada and the Canada Research Chairs program.

\section{Literature Cited}

Addo-Bediako A., S.L. Chown, and K.J. Gaston. 2000. Thermal tolerance, climatic variability and latitude. Proc R Soc Lond B 267:739-745.

Allen A.P., J.H. Brown, and J.F. Gillooly. 2002. Global biodiversity, biochemical kinetics, and the energetic-equivalence rule. Science 297:1545-1548.

Andrewartha H.G. and L.C. Birch. 1954. The Distribution and Abundance of Animals. University of Chicago Press, Chicago.

Angilletta M.J., Jr., P.H. Niewiarowski, and C.A. Navas. 2002. The evolution of thermal physiology in ectotherms. J Therm Biol 27:249-268.

Ayrinhac A., V. Debat, P. Gibert, A.-G. Kister, H. Legout, B. Moreteau, R. Vergilino, and J.R. David. 2004. Cold adaptation in geographical populations of Drosophila melanogaster: phenotypic plasticity is more important than genetic variability. Funct Ecol 18:700-706.

Berriel Diaz M., M. Lange, G. Heldmaier, and M. Klingenspor. 2004. Depression of transcription and translation during daily torpor in the Djungarian hamster (Phodopus sungorus). J Comp Physiol B 174:495-502.

Bickler P.E., P.H. Donohoe, and L.T. Buck. 2002. Molecular adaptations for survival during anoxia: lessons from lower vertebrates. Neuroscientist 8:234-242.

Brooks D.R. and E.O. Wiley. 1988. Evolution as Entropy: Toward a Unified Theory of Biology. University of Chicago Press, Chicago.

Brown J.H., J.F. Gillooly, A.P. Allen, V.M. Savage, and G.B. West. 2004a. Toward a metabolic theory of ecology. Ecology 85: 1771-1789.

- 2004b. Response to forum commentary on "Toward a metabolic theory of ecology." Ecology 85:1818-1821.

Cai Q. and K.B. Storey. 1996. Anoxia-induced gene expression in turtle heart: up-regulation of mitochondrial genes for NADH-ubiquinone oxidoreductase subunit 5 and cytochrome C oxidase subunit 1. Eur J Biochem 241:83-92.

Chen C.-P., R.E. Lee, and D.L. Denlinger. 1990. A comparison of the responses of tropical and temperate flies (Diptera: Sarcophagidae) to cold and heat stress. J Comp Physiol B 160:543-547.

Chown S.L. 2001. Physiological variation in insects: hierarchical levels and implications. J Insect Physiol 47:649-660.

Chown S.L., A. Addo-Bediako, and K.J. Gaston. 2003. Physiological diversity: listening to the large-scale signal. Funct Ecol 17:562-572.

Chown S.L. and A. Clarke. 2000. Stress and the geographic distribution of marine and terrestrial animals. Pp. 41-54 in K.B. Storey and J.M. Storey, eds. Cell and Molecular Responses to Stress. Elsevier, Amsterdam.

Chown S.L., K.J. Gaston, and D. Robinson. 2004. Macrophysiology: large-scale patterns in physiological traits and their ecological implications. Funct Ecol 18:159-167.

Chown S.L. and S.W. Nicolson. 2004. Insect Physiological Ecology: Mechanisms and Patterns. Oxford University Press, Oxford.

Clarke A. 1996. The influence of climate change on the distribution and evolution of organisms. Pp. 377-407 in I.A. Johnston and A.F. Bennett, eds. Animals and Temperature: Phenotypic and Evolutionary Adaptation. Cambridge University Press, Cambridge.

- 2004. Is there a universal temperature dependence of metabolism? Funct Ecol 18:252-256.

Clarke A. and K.P.P. Fraser. 2004. Why does metabolism scale with temperature? Funct Ecol 18:243-251.

Cohen J.E. 1996. How Many People Can the Earth Support? Norton, New York.

Cossins A.R. and K. Bowler. 1987. Temperature Biology of Animals. Chapman \& Hall, London.

Cyr H. and S.C. Walker. 2004. An illusion of mechanistic understanding. Ecology 85:1802-1804.

Dahlhoff E.P. and N.E. Rank. 2000. Functional and physiological consequences of genetic variation at phosphoglucose isomerase: heat shock protein expression is related to enzyme genotype in a montane beetle. Proc Natl Acad Sci USA 97: 10056-10061. 
Dausmann K.H., J. Glos, J.U. Ganzhorn, and G. Heldmaier. 2004. Physiology: hibernation in a tropical primate. Nature 429:825-826.

Davis M.B. and R.G. Shaw. 2001. Range shifts and adaptive responses to Quaternary climate change. Science 292:673679.

Denlinger D.L. and R.E. Lee. 1998. Physiology of cold sensitivity. Pp. 55-95 in G.J. Hallman and D.L. Denlinger, eds. Temperature Sensitivity in Insects and Application in Integrated Pest Management. Westview, Boulder, CO.

Denlinger D.L., R.E. Lee, G.D. Yocum, and O. Kukal. 1992. Role of chilling in the acquisition of cold tolerance and the capacitation to express stress proteins in diapausing pharate larvae of the gypsy moth, Lymantria dispar. Arch Insect Biochem Physiol 21:271-280.

Denlinger D.L., J.P. Rinehart, and G.D. Yocum. 2001. Stress proteins: a role in insect diapause? Pp. 155-171 in D.L. Denlinger, J. Giebultowicz, and D.S. Saunders, eds. Insect Timing: Circadian Rhythmicity to Seasonality. Elsevier, Amsterdam.

Denlinger D.L. and G.D. Yocum. 1998. Physiology of heat sensitivity. Pp. 7-53 in G.J. Hallman and D.L. Denlinger, eds. Temperature Sensitivity in Insects and Application in Integrated Pest Management. Westview, Boulder, CO.

Dodds P.S., D.H. Rothman, and J.S. Weitz. 2001. Re-examination of the "3/4-law" of metabolism. J Theor Biol 209:927.

Evans K.L., P.H. Warren, and K.J. Gaston. 2005. Species-energy relationships at the macroecological scale: a review of the mechanisms. Biol Rev 80:1-25.

Feder M.E., A.F. Bennett, and R.B. Huey. 2000. Evolutionary physiology. Annu Rev Ecol Syst 31:315-341.

Feder M.E., N. Blair, and H. Figueras. 1997. Natural thermal stress and heat-shock protein expression in Drosophila larvae and pupae. Funct Ecol 11:90-100.

Finkel Z.V., A.J. Irwin, and O. Schofield. 2004. Resource limitation alters the $3 / 4$ size scaling of metabolic rates in phytoplankton. Mar Ecol Prog Ser 273:269-279.

Garland T. and P.A. Carter. 1994. Evolutionary physiology. Annu Rev Physiol 56:579-621.

Gaston K.J. 2003. The Structure and Dynamics of Geographic Ranges. Oxford University Press, Oxford.

- 2004. Macroecology and people. Basic Appl Ecol 5: 303-307.

Gilchrist G.W., R.B. Huey, and L. Partridge. 1997. Thermal sensitivity of Drosophila melanogaster: evolutionary responses of adults and eggs to laboratory natural selection at different temperatures. Physiol Zool 70:403-414.

Gillooly J.F., J.H. Brown, G.B. West, V.M. Savage, and E.L. Charnov. 2001. Effects of size and temperature on metabolic rate. Science 293:2248-2251.

Goto S.G. and M.T. Kimura. 1998. Heat- and cold-shock responses and temperature adaptations in subtropical and temperate species of Drosophila. J Insect Physiol 44:1233-1239.
Greenway S.C. and K.B. Storey. 2000. Mitogen-activated protein kinases and anoxia tolerance in turtles. J Exp Zool 287:477484.

Haman F., S.R. Legault, M. Rakobowchuk, M.B. Ducharme, and J.M. Weber. 2004a. Effects of carbohydrate availability on sustained shivering. II. Relating muscle recruitment to fuel selection. J Appl Physiol 96:41-49.

Haman F., S.R. Legault, and J.M. Weber. 2004b. Fuel selection during intense shivering in humans: EMG pattern reflects carbohydrate oxidation. J Physiol 556:305-313.

Haman F., F. Peronnet, G.P. Kenny, E. Doucet, D. Massicotte, C. Lavoie, and J.M. Weber. 2004c. Effects of carbohydrate availability on sustained shivering. I. Oxidation of plasma glucose, muscle glycogen, and proteins. J Appl Physiol 96: 32-40.

Haman F., F. Peronnet, G.P. Kenny, D. Massicotte, C. Lavoie, C. Scott, and J.M. Weber. 2002. Effect of cold exposure on fuel utilization in humans: plasma glucose, muscle glycogen, and lipids. J Appl Physiol 93:77-84.

Hawkins B.A., R. Field, H.V. Cornell, D.J. Currie, J.F. Guegan, D.M. Kaufman, J.T. Kerr, et al. 2003. Energy, water, and broad-scale geographic patterns of species richness. Ecology 84:3105-3117.

Hayward S.A.L., J.P. Rinehart, and D.L. Denlinger. 2004. Desiccation and rehydration elicit distinct heat shock protein transcript responses in flesh fly pupae. J Exp Biol 207:963971.

Heldmaier G., M. Klingenspor, M. Werneyer, B.J. Lampi, S.P.J. Brooks, and K.B. Storey. 1999. Metabolic adjustments during daily torpor in the Djungarian hamster. Am J Physiol 276: E896-E906.

Heldmaier G., S. Ortmann, and R. Elvert. 2004. Natural hypometabolism during hibernation and daily torpor in mammals. Respir Physiol Neurobiol 141:317-329.

Hochachka P.W. and G.N. Somero. 2002. Biochemical Adaptation: Mechanisms and Process in Physiological Evolution. Oxford University Press, New York.

Hoffmann A.A., A. Anderson, and R. Hallas. 2002. Opposing clines for high and low temperature resistance in Drosophila melanogaster. Ecol Lett 5:614-618.

Hoffmann A.A., H. Dagher, M. Hercus, and D. Berrigan. 1997. Comparing different measures of heat resistance in selected lines of Drosophila melanogaster. J Insect Physiol 43:393-405.

Hoffmann A.A., J.G. Sørensen, and V. Loeschcke. 2003. Adaptation of Drosophila to temperature extremes: bringing together quantitative and molecular approaches. J Therm Biol 28:175-216.

Hosler J.S., J.E. Burns, and H.E. Esch. 2000. Flight muscle resting potential and species-specific differences in chill coma. J Insect Physiol 46:621-627.

Huey R.B. 1987. Phylogeny, history, and the comparative method. Pp. 76-101 in M.E. Feder, A.F. Bennett, W.W. Burg- 
gren, and R.B. Huey, eds. New Directions in Ecological Physiology. Cambridge University Press, Cambridge.

Jackson D.C. 1968. Metabolic depression and oxygen depletion in the diving turtle. J Appl Physiol 24:503-509.

2000. Living without oxygen: lessons from the freshwater turtle. Comp Biochem Physiol A 125:299-315.

- 2002. Hibernating without oxygen: physiological adaptations of the painted turtle. J Physiol 543:731-737.

- 2004. Acid-base balance during hypoxic hypometabolism: selected vertebrate strategies. Respir Physiol Neurobiol 141:273-283.

Kauffman S.A. 1993. The Origins of Order: Self Organization and Selection in Evolution. Oxford University Press, Oxford.

Kelty J.D. and R.E. Lee. 2001. Rapid cold-hardening of Drosophila melanogaster (Diptera: Drosophilidae) during ecologically based thermoperiodic cycles. J Exp Biol 204:16591666.

Klok C.J. and S.L. Chown. 2003. Resistance to temperature extremes in sub-Antarctic weevils: interspecific variation, population differentiation and acclimation. Biol J Linn Soc 78:401-414.

Klok C.J., B.J. Sinclair, and S.L. Chown. 2004. Upper thermal tolerance and oxygen limitation in terrestrial arthropods. J Exp Biol 207:2361-2370.

Koštál V., J. Vambera, and J. Bastl. 2004. On the nature of prefreeze mortality in insects: water balance, ion homeostasis and energy charge in the adults of Pyrrhocoris apterus. J Exp Biol 207:1509-1521.

Kozłowski J. and Konarzewski, M. 2004. Is West, Brown and Enquist's model of allometric scaling mathematically correct and biologically relevant? Funct Ecol 18:283-289.

Lee R.E., C.-P. Chen, and D.L. Denlinger. 1987. A rapid coldhardening process in insects. Science 238:1415-1417.

Li B.L., V.G. Gorshkov, and A.M. Makarieva. 2004. Energy partitioning between different-sized organisms and ecosystem stability. Ecology 85:1811-1813.

Lutz P.L. and S.L. Milton. 2004. Negotiating brain anoxia survival in the turtle. J Exp Biol 207:3141-3147.

McNab B.K. 2003. The Physiological Ecology of Vertebrates: A View from Energetics. Cornell University Press, Ithaca, NY.

Messenger P.S. 1959. Bioclimatic studies with insects. Annu Rev Entomol 4:183-206.

Ortega y Gasset J. 1930. The Revolt of the Masses. Norton, New York.

Parmesan C. and G. Yohe. 2003. A globally coherent fingerprint of climate change impacts across natural systems. Nature 421 : 37-42.

Parsons P.A. 1981. Evolutionary ecology of Australian Drosophila: a species analysis. Evol Biol 14:297-350.

Pörtner H.O. 2001. Climate change and temperature-dependent biogeography: oxygen limitation of thermal tolerance in animals. Naturwissenschaften 88:137-146.

- 2002. Climate variations and the physiological basis of temperature dependent biogeography: systemic to molecular hierarchy of thermal tolerance in animals. Comp Biochem Physiol A 132:739-761.

Prosser C.L. 1986. Adaptational Biology: Molecules to Organisms. Wiley, New York.

Ramløv H. 2000. Aspects of natural cold tolerance in ectothermic animals. Hum Reprod 15:26-46.

Reese S.A., C.E. Crocker, D.C. Jackson, and G.R. Ultsch. 2001. The physiology of hibernation among painted turtles: the midland painted turtle (Chrysemys picta marginata). Respir Physiol 124:43-50.

Reese S.A., D.C. Jackson, and G.R. Ultsch. 2003. Hibernation in freshwater turtles: softshell turtles (Apalone spinifera) are the most intolerant of anoxia among North American species. J Comp Physiol B 173:263-268.

Ricklefs R.E. 2003. Is rate of ontogenetic growth constrained by resource supply or tissue growth potential? a comment on West et al.'s model. Funct Ecol 17:384-393.

Rinehart J.P., G.D. Yocum, and D.L. Denlinger. 2000. Developmental upregulation of inducible $h s p 70$ transcripts, but not the cognate form, during pupal diapause in the flesh fly, Sarcophaga crassipalpis. Insect Biochem Mol Biol 30:515-521.

Roff D.A. 1992. The Evolution of Life Histories: Theory and Analysis. Chapman \& Hall, London.

Rohde K. 1992. Latitudinal gradients in species diversity: the search for the primary cause. Oikos 65:514-527.

Root T.L., J.T. Price, K.R. Hall, S.H. Schneider, C. Rosenzweig, and J.A. Pounds. 2003. Fingerprints of global warming on wild animals and plants. Nature 421:57-60.

Sala O.E., F.S. Chapin, J.J. Armesto, E. Berlow, J. Bloomfield, R. Dirzo, E. Huber-Sanwald, et al. 2000. Global biodiversity scenarios for the year 2100. Science 287:1770-1774.

Savage V.M., J.F. Gillooly, J.H. Brown, G.B. West, and E.L. Charnov. 2004. Effects of body size and temperature on population growth. Am Nat 163:E429-E441.

Scholander P.F., W. Flagg, V. Walters, and L. Irving. 1953. Climatic adaptation in Arctic and Tropical poikilotherms. Physiol Zool 26:67-92.

Sgrò C.M. and M.W. Blows. 2004. The genetic covariance among clinal environments after adaptation to an environmental gradient in Drosophila serrata. Genetics 167:12811291.

Shelford V.E. 1911. Physiological animal geography. J Morphol 22:551-618.

Sinclair B.J. and S.L. Chown. 2003. Rapid responses to high temperature and desiccation but not to low temperature in the freeze tolerant sub-Antarctic caterpillar Pringleophaga marioni (Lepidoptera, Tineidae). J Insect Physiol 49:45-52.

Sinclair B.J., C.J. Klok, and S.L. Chown. 2004. Metabolism of the sub-Antarctic caterpillar Pringleohaga marioni during cooling, freezing and thawing. J Exp Biol 207:1287-1294.

Sørensen J.G., J. Dahlgaard, and V. Loeschcke. 2001. Genetic variation in thermal tolerance among natural populations of 
Drosophila buzzatii: down regulation of Hsp70 expression and variation in heat stress resistance traits. Funct Ecol 15: 289-296.

Spicer J.I. and K.J. Gaston. 1999. Physiological Diversity and Its Ecological Implications. Blackwell Science, Oxford.

Stearns S.C. 1992. The Evolution of Life Histories. Oxford University Press, Oxford.

Sterner R.W. 2004. A one-resource "stoichiometry"? Ecology 85:1813-1816.

Stillman J.H. 2003. Acclimation capacity underlies susceptibility to climate change. Science 301:65.

Stillman J.H. and G.N. Somero. 2000. A comparative analysis of the upper thermal tolerance limits of eastern Pacific porcelain crabs, genus Petrolisthes: influences of latitude, vertical zonation, acclimation, and phylogeny. Physiol Biochem Zool 73:200-208.

Storey K.B. 2004a. Functional Metabolism: Regulation and Adaptation. Wiley-Liss, Hoboken, NJ.

- 2004b. Molecular mechanisms of anoxia tolerance. Int Congr Ser 1275:47-54.

Storey K.B. and J.M. Storey. 2000. Cell and Molecular Responses to Stress. Elsevier, Amsterdam.

- 2004. Metabolic rate depression in animals: transcriptional and translational controls. Biol Rev 79:207-233.

Symonds M.R.E. and M.A. Elgar. 2002. Phylogeny affects estimation of metabolic scaling in mammals. Evolution 56: 2330-2333.

Thomas C.D., A. Cameron, R.E. Green, M. Bakkenes, L.J. Beaumont, Y.C. Collingham, B.F.N. Erasmus, et al. 2004. Extinction risk from climate change. Nature 427:145-148.

Tilman D., K.G. Cassman, P.A. Matson, R. Naylor, and S. Polasky. 2002. Agricultural sustainability and intensive production practices. Nature 418:671-677.

Tilman D., J. HilleRisLambers, S. Harpole, R. Dybzinski, J. Fargione, C. Clark, and C. Lehman. 2004. Does metabolic theory apply to community ecology? it's a matter of scale. Ecology 85:1797-1799.

Ultsch G.R. 1989. Ecology and physiology of hibernation and overwintering in freshwater fishes, turtles and snakes. Biol Rev 64:435-516.

van der Have T.M. 2002. A proximate model for thermal tolerance in ectotherms. Oikos 98:141-155.

Walther G.-R., E. Post, P. Convey, A. Menzel, C. Parmesan, T.J.C. Beebee, J.-M. Fromentin, O. Hoegh-Guldberg, and F. Bairlein. 2002. Ecological responses to recent climate change. Nature 416:389-395.
Watson R.T. 2002. Climate Change 2001: Synthesis Report. Cambridge University Press, Cambridge.

West G.B., J.H. Brown, and B.J. Enquist. 1997. A general model for the origin of allometric scaling laws in biology. Science 276:122-126.

1999. The fourth dimension of life: fractal geometry and allometric scaling of organisms. Science 284:1677-1679.

2001. A general model for ontogenetic growth. Nature 413:628-631.

West G.B., W.H. Woodruff, and J.H. Brown. 2002. Allometric scaling of metabolic rate from molecules and mitochondria to cells and mammals. Proc Natl Acad Sci USA 99:24732478.

Willig M.R., D.M. Kaufman, and R.D. Stevens. 2003. Latitudinal gradients of biodiversity: pattern, process, scale and synthesis. Annu Rev Ecol Evol Syst 34:273-309.

Willmore W.G., T.E. English, and K.B. Storey. 2001. Mitochondrial gene responses to low oxygen stress in turtle organs. Copeia 2001:628-637.

Woods H.A. and R.I. Hill. 2004. Temperature-dependent oxygen limitation in insect eggs. J Exp Biol 207:2267-2276.

Yocum G.D. 2001. Differential expression of two HSP70 transcripts in response to cold shock, thermoperiod, and adult diapause in the Colorado potato beetle. J Insect Physiol 47: 1139-1145.

Yocum G.D., K.H. Joplin, and D.L. Denlinger. 1991. Expression of heat shock proteins in response to high and low temperatures in diapausing pharate larvae of the gypsy moth, $L y$ mantria dispar. Arch Insect Biochem Physiol 18:239-249.

Zatsepina O.G., V.V. Velikodvorskaia, V.B. Molodtsov, D. Garbuz, D.N. Lerman, B.R. Bettencourt, M.E. Feder, and M.B. Evgenev. 2001. A Drosophila melanogaster strain from subequatorial Africa has exceptional thermotolerance but decreased Hsp70 expression. J Exp Biol 204:1869-1881.

Zera A.J. 2004. The endocrine regulation of wing polymorphism in insects: state of the art, recent surprises, and future directions. Integr Comp Biol 43:607-616.

Zera A.J. and Zhao Z.W. 2004. Effect of a juvenile hormone analogue on lipid metabolism in a wing-polymorphic cricket: implications for the endocrine-biochemical bases of lifehistory trade-offs. Physiol Biochem Zool 77:255-266.

Zhao Z. and A.J. Zera. 2002. Differential lipid biosynthesis underlies a tradeoff between reproduction and flight capability in a wing-polymorphic cricket. Proc Natl Acad Sci USA 99:16829-16834. 